\title{
Platelet Storage Pool Deficiency and Elevated Inflammatory Biomarkers Are Prevalent in Postural Orthostatic Tachycardia Syndrome
}

\author{
William T. Gunning ${ }^{1, * \mathbb{D}}$, Paula M. Kramer ${ }^{1}$, Jacob A. Cichocki ${ }^{1}$, Beverly L. Karabin ${ }^{2}$, Sadik A. Khuder ${ }^{2}$ \\ and Blair P. Grubb 2 (D) \\ 1 Department of Pathology, University of Toledo, Toledo, OH 43614, USA; paula.kramer2@utoledo.edu (P.M.K.); \\ jacob.cichocki@utoledo.edu (J.A.C.) \\ 2 Department of Medicine, University of Toledo, Toledo, OH 43614, USA; beverly.karabin@utoledo.edu (B.L.K.); \\ sadik.khuder@utoledo.edu (S.A.K.); blair.grubb@utoledo.edu (B.P.G.) \\ * Correspondence: william.gunning@utoledo.edu
}

check for

updates

Citation: Gunning, W.T.; Kramer, P.M.; Cichocki, J.A.; Karabin, B.L.; Khuder, S.A.; Grubb, B.P. Platelet Storage Pool Deficiency and Elevated Inflammatory Biomarkers Are Prevalent in Postural Orthostatic

Tachycardia Syndrome. Cells 2022, 11, 774. https://doi.org/10.3390/ cells11050774

Academic Editors: Alessandro Poggi and Smaragdi Antonopoulou

Received: 24 January 2022

Accepted: 18 February 2022

Published: 23 February 2022

Publisher's Note: MDPI stays neutral with regard to jurisdictional claims in published maps and institutional affiliations.

Copyright: (c) 2022 by the authors. Licensee MDPI, Basel, Switzerland. This article is an open access article distributed under the terms and conditions of the Creative Commons Attribution (CC BY) license (https:// creativecommons.org/licenses/by/ $4.0 /)$.

\begin{abstract}
A significant number of postural orthostatic tachycardia syndrome (POTS) patients have platelet delta granule storage pool deficiency ( $\delta$-SPD). The etiology of POTS is unknown but a number of laboratories, including ours, have reported elevations of G-protein-coupled adrenergic receptor and muscarinic acetylcholine receptor autoantibodies in POTS patients, detected by a variety of techniques, suggesting that the disorder is an autoimmune condition. Thus, it could also be considered an inflammatory disease. In a pilot study, we investigated a limited number of platelet-related cytokines and chemokines and discovered many that were elevated. This case-control study validates our pilot study results that POTS patients have an activated innate immune system. Plasma of 35 POTS patients and 35 patients with unexplained bleeding symptoms and categorized as "non-POTS" subjects was analyzed by multiplex flow cytometry to quantify 16 different innate immune system cytokines and chemokines. Electron microscopy was used to quantify platelet dense granules. Ten of 16 biomarkers of inflammation were elevated in plasma from POTS patients compared to non-POTS subjects, with most of the differences extremely significant, with $p$ values $<0.0001$. Of particular interest were elevations of IL-1 $\beta$ and IL-18 and decreased or normal levels of type 1 interferons in POTS patients, suggesting that the etiology of POTS might be autoinflammatory. All POTS patients had $\delta$-SPD. With a growing body of evidence that POTS is an autoimmune disease and having elevations of the innate immune system, our results suggest a potential T-cell-mediated autoimmunity in POTS characteristic of a mixed-pattern inflammatory disease similar to rheumatoid arthritis.
\end{abstract}

Keywords: POTS; tachycardia; cytokine; inflammation; syncope; platelet; storage pool deficiency; innate immune system activation

\section{Introduction}

Postural orthostatic tachycardia syndrome (POTS) is a condition of orthostatic intolerance with a racing heart and a multitude of symptoms, induced upon standing and relieved when becoming supine [1]. Common nonspecific symptoms reported with POTS include exercise intolerance, fatigue, lightheadedness, palpitations, nausea, headache, diminished concentration ("brain fog"), near syncope, and syncope. It is a debilitating disorder, affecting an estimated $1 \%$ of the population and likely more with the numerous reports in the literature of COVID-19 "long haulers" exhibiting many of the symptoms described by POTS patients; a number of these patients have actually been diagnosed with POTS [2-6]. The disorder was likely first described in 1871 by Da Costa, who described all of the features of POTS mentioned above; it was formally monikered in 1993 by Schondorf and Low, yet, even today, it is not well recognized in the medical community, nor has an etiology been established [1,7]. Unfortunately, as many as $75 \%$ of affected individuals are misdiagnosed 
or referred for psychological consultation [8-11]. The diagnosis requires the presence of chronic orthostatic intolerance associated with an increased heart rate of $\geq 30$ beats per minute (BPM) from the supine or sitting basal rate, or a rate that exceeds 120 BPM when standing or by an upright tilt test that occurs within $10 \mathrm{~min}$ [1,12]. There is also an absence of orthostatic hypotension, a duration of symptoms for at least 6 months, and the absence of a number of conditions that could explain sinus tachycardia [1]. There is a growing body of evidence suggesting that POTS is an autoimmune disease [13-18].

We have reported that a number of symptoms observed in POTS may be related to a platelet deficiency of granules that contain stores of serotonin, called platelet delta granule storage pool deficiency ( $\delta$-SPD) [8]. Platelet $\delta$-SPD is an autosomal dominant inherited disorder but may also be acquired; there are many documented genetic associations including autoimmune diseases $[9,10]$. We have empirical evidence that the acquired $\delta$-SPD may be related to viral infection and/or chronic inflammation and, based upon this, we explored a number of cytokines and chemokines related to platelet activation in a limited number of POTS patients that had elevations of G-protein-linked autoantibodies against the alpha 1 adrenergic receptor [11]. We reported that a number of inflammatory biomarkers were significantly elevated, but, as a pilot study, our experimental design was incomplete. The platelet is an essential element of the innate immune system, especially in defense of viral infections [12-14]. With associations of viral infections as a potential etiology of POTS and evidence that many COVID-19 long haulers are developing POTS, platelets may also play a significant role in the etiology or perpetuation of the disorder.

The purpose of the current study was to expand the number of inflammatory biomarkers we had previously evaluated in a case-control study of POTS and non-POTS patients. Our hypothesis was that POTS has elevations of cytokines and chemokines indicating innate immune cell activation characteristic of an autoinflammatory disease. These biochemicals may be induced by the release of substances contained in the platelet storage pool that prolong autoimmunity. The specific aims of the investigation were (1) to determine the potential that POTS might be an autoinflammatory condition rather than an autoimmune disease, and (2) to validate our previous results that POTS patients have significant elevations of innate immune system biochemicals that are related to the platelet as an immune cell.

\section{Materials and Methods}

\subsection{Patients}

Our retrospective case-control study was approved by the Institutional Review Board of The University of Toledo Medical Center. Platelet-poor plasma (PPP) from 35 patients diagnosed with POTS and 35 patients without POTS was assayed for a number of biomarkers of inflammation that we have previously reported [11]. The specific inflammatory biomarkers included in this investigation were selected based upon descriptions in the literature related to platelet activation [15-20]. All POTS patients had histories of orthostatic intolerance manifested by orthostatic tachycardia, weakness, light-headedness, fatigue, and near syncope for at least 6 months or longer and were diagnosed with primary POTS in our Syncope and Autonomic Disorders Clinic. The diagnosis was based upon clinical history, physical examination, and head-upright tilt table analysis in the fasting state. Blood chemistry analysis and thyroid profile analysis were included during diagnostic workups. These patients had also exhibited bleeding symptoms and peripheral blood had been submitted to assess platelet dense granules for $\delta$-SPD to explain these symptoms. The control subjects did not include anyone diagnosed with POTS, but they had been evaluated for a potential platelet function disorder and found to have a normal number of platelet dense granules.

All subjects had a complete blood cell count (CBC) and a mean number of platelet dense granules determined. We have previously reported that more than $80 \%$ of patients diagnosed with POTS have $\delta$-SPD. 


\subsection{Platelet Preparations for Electron Microscopy}

Platelet-rich plasma (PRP) was obtained from whole blood by centrifugation at room temperature for $15 \mathrm{~min}$ at $200 \mathrm{~g}$. Electron microscopy coated copper grids used for platelet support were washed with deionized water following PRP incubation and air-dried. A FEI Tecnai G2 Spirit BioTwin transmission electron microscope (TEM, Hillsboro, OR) was used to determine the average number of DG/PL (Figure 1). Previous studies from this laboratory have established a normal value of $4.64 \pm 0.11$ (mean \pm 1 SE DG/PL), consistent with the established literature $[9,21,22]$.

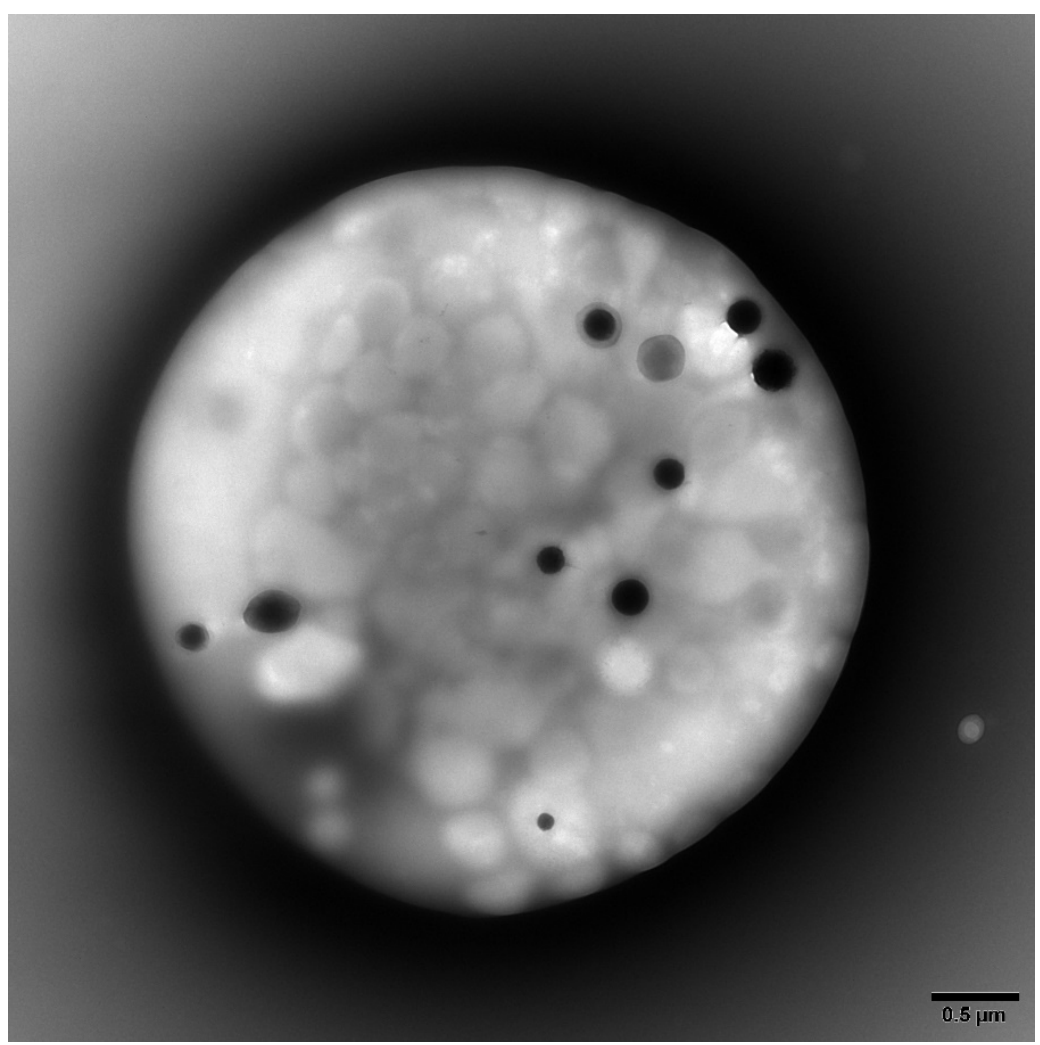

Figure 1. Representative transmission electron microscopy image of a whole mounted and air-dried platelet. Dense granules appear as opaque round bodies (normal =4-6/platelet; range 0-30/platelet), whereas the ill-defined gray bodies are alpha granules (50-80/platelet).

\subsection{Inflammation Biomarker Preparations}

A custom RayPlex ${ }^{\circledR}$ Human Multiplex Bead Array was purchased to assess 16 cytokine/chemokine biomarkers from RayBiotech, Inc. (Peachtree Corners, GA 30092, USA), including IL-1 $\beta$, IL-6, IL-8, IL-10, IL-17, IL-18, IL-21, INF $\alpha$, INF $\beta$, INF $\gamma$, TNF $\alpha$, CD30, CD40, sCD40L (CD154), MCP-1 (chemokine ligand 2/CCL2), and CCL5 (RANTES), all of which have been associated with inflammation and/or platelet activation. The multiplex bead system for flow cytometry allowed for simultaneous quantification of the cytokines/chemokines. During validation of the custom beads, it was determined that INF $\alpha$ could not be included due to detection limits, and a standard sandwich-based ELISA was utilized to quantitate the interferon. Validation and quantitation for all targets was made by comparison with specific protein concentrations for each cytokine/chemokine from standard curves. All samples were analyzed by RayBiotech in Peachtree Corners, Georgia.

\subsection{Statistical Methods}

Unless otherwise stated, data are presented as mean +1 standard error of the mean (SE). Descriptive statistics were calculated using $\mathrm{R}$ statistical software (R Core Team, $\mathrm{R}$ Foundation for Statistical Computing, Vienna, Austria. URL https://www.R-project.org/, 
accessed on 2 August 2021). Univariate analysis of variance, Tukey HSD, and linear discriminant analysis were utilized to analyze cytokine and chemokine concentration variances between groups, and a Student $t$ test and Mann-Whitney Rank Sum test were used to compare the mean PL/DG and CBC results between groups. SigmaPlot software (version 14.5, Systat Software, Inc. Palo Alto, CA, USA) was also used to produce graphs for the manuscript.

\section{Results}

The mean age of subjects in study groups was not statistically different (mean age for POTS patients was $22.2 \pm 2.9$ and non-POTS subjects was $22.0 \pm 2.0)$. However, POTS patients were found to have a mean of $2.65 \pm 0.22 \mathrm{DG} / \mathrm{PL}$ (normal $=4.64 \pm 0.11$ ), which is consistent with $\delta$-SPD, in contrast to non-POTS subjects, who had normal numbers of DGs $(4.95 \pm 0.11 \mathrm{DG} / \mathrm{PL})(p<0.0001)$. There was no statistical correlation found with any of the hematologic factors measured (CBCs), except the hematocrit between groups. The POTS patients had a lower hematocrit (33.1\%; lower than normal (36.1-44.3\%)) compared with non-POTS subjects $(44.1 \%, p<0.008)$.

Highly significant differences were found between groups for $11 / 16$ of the cytokine/ chemokine plasma concentrations evaluated (Table 1). Differences in IL-1 $\beta$, IL-10, IL$17, \mathrm{INF} \gamma$, and RANTES (CCL5) were striking, with each having $p$ values $<0.0001$. All differences identified were increased concentrations of innate immune cytokines in POTS subjects, except for the type 1 interferon INF $\alpha$, which was decreased in POTS $(0.06 \pm 0.04)$ when compared to the plasma concentration of the control group $(223 \pm 67, p<0.002)$. No difference was found between groups for CD40, CD40L (CD154), IL-8, INF $\beta$, or TNF $\alpha$.

Table 1. Inflammatory biomarkers in POTS patients.

\begin{tabular}{|c|c|c|c|c|c|}
\hline $\begin{array}{l}\text { Cytokine/ } \\
\text { Chemokine }\end{array}$ & $\begin{array}{c}\text { POTS } \\
(n=35) \\
(\mathrm{pg} / \mathrm{mL})\end{array}$ & $\begin{array}{c}\text { Non-POTS } \\
(n=35) \\
(\mathrm{pg} / \mathrm{mL})\end{array}$ & $p$ Value & Source & Major Function \\
\hline CD30 & $3638 \pm 822$ & $160 \pm 12$ & $p<0.0002$ & Activated $\mathrm{T}$ and $\mathrm{B}$ & Regulates cell proliferation \\
\hline CD40 & $340 \pm 165$ & $452 \pm 171$ & ns & B cell, Mac & TLR7 PLT-neutrophil tethering \\
\hline CD40 L (CD154) & $31 \pm 13$ & $6.7 \pm 0.8$ & ns & Platelets, Mono & Recruits neutrophils and monocytes \\
\hline IL $1 \beta$ & $38 \pm 8$ & $4.4 \pm 0.9$ & $p<0.0001$ & Mono/Mac, PLTs & Proinflammatory \\
\hline IL-6 & $119 \pm 18$ & $58 \pm 9$ & $p<0.003$ & Th Cells, Mac & Differentiates B cells to plasma cells \\
\hline IL-8 (CXCL8) & $145 \pm 49$ & $157 \pm 25$ & ns & Mono, Neutro & Chemotaxis, proinflammatory \\
\hline IL 10 & $24 \pm 4$ & $5.5 \pm 1.0$ & $p<0.0001$ & $\mathrm{~T}$ cell & Anti-inflammatory \\
\hline IL-17 & $93 \pm 20$ & $4.2 \pm 0.7$ & $p<0.0001$ & Th17 & Proinflammatory \\
\hline IL-18 & $207 \pm 67$ & $21 \pm 9$ & $p<0.009$ & Mono & Proinflammatory, IL-1 family \\
\hline IL 21 & $9025 \pm 1875$ & $2937 \pm 517$ & $p<0.003$ & $\mathrm{~T}$ cell & Controls NK and T cells \\
\hline $\mathrm{INF} \alpha$ & $0.06 \pm 0.04$ & $223 \pm 67$ & $p<0.002$ & Leukocytes & Anti-viral, phagocyte cell activation \\
\hline $\mathrm{INF} \beta$ & $8219 \pm 2230$ & $6334 \pm 3267$ & ns & Fibroblasts & Anti-viral, anti-proliferative \\
\hline INF $\gamma$ & $8.5 \pm 1.7$ & $1.2 \pm 0.2$ & $p<0.0001$ & $\mathrm{NK}, \mathrm{Th}_{1}$ & $\begin{array}{l}\text { Antiviral, increases Neut and } \\
\text { Mono function }\end{array}$ \\
\hline MCP1 (CCL2) & $441 \pm 102$ & $13 \pm 2$ & $p<0.0002$ & Endo, PLT & Recruits monocytes \\
\hline RANTES (CCL5) & $13706 \pm 3022$ & $517 \pm 297$ & $p<0.0001$ & Platelet, NK, T & Chemotactic for T cells \\
\hline $\mathrm{TNF} \alpha$ & $972 \pm 250$ & $506 \pm 120$ & ns & Mono, NK & Proinflammatory \\
\hline
\end{tabular}

Elevations of cytokines/chemokines are in red font. Decreases in cytokines/chemokines in blue font.

\section{Discussion}

This case-control study was intended to validate a pilot study of inflammatory biomarkers, presumably related to platelets, obtained from POTS patients having ele- 
vated G-protein-coupled autoantibodies [11]. Platelets play a crucial role in hemostasis but also have a significant role in both innate and adaptive immunity [16,23,24]. Platelets contain cytokines and chemokines known to modulate the effects of leukocytes as either pro- or anti- inflammatory agents $[16,25,26]$.

Our pilot study provided data that suggested that the innate immune system might have a significant role in the etiology of POTS. In fact, our limited data suggested that POTS could be T-cell-mediated. Unfortunately, we did not include an investigation of type 1 interferons to allow us to distinguish an autoinflammatory process from autoimmunity. In addition, we did not evaluate IL-17 levels in plasma; the cytokine plays a significant role in both innate and adaptive immune responses and there is a growing body of evidence suggesting that IL-17 is elevated in autoimmune disorders $[27,28]$.

Specific aim 1 addressed the potential that POTS might be an autoinflammatory condition rather than an autoimmune disease. To evaluate this, we measured the plasma concentrations of IL-1 $\beta$, IL-18 (an IL- 1 "family" member), the type 1 interferons INF $\alpha$ and INF $\beta$, and the type 2 interferon INF $\gamma$. IL- 1 and type I interferons are diametrically opposed; inflammatory disorders with elevations of IL-1 are categorized as autoinflammatory whereas conditions with elevations of type 1 interferons are characteristic of autoimmune diseases $[29,30]$. POTS patients evaluated in this study had significant elevations of IL-1 $\beta$ compared to non-POTS subjects $(p<0.0001)$, as well as elevations of IL-18 $(p<0.009)$. Interferon alpha was significantly decreased in POTS compared to non-POTS subjects $(p<0.002)$, whereas no significant difference was found for plasma levels of INF $\beta$. Elevations of type 1 INF appear to be critical mediators of autoimmune disease [31]. These data provide evidence that POTS is an autoinflammatory condition. However, we and others have reported that POTS appears to be an autoimmune disorder based upon the identification of a variety of autoantibodies detected in the blood of POTS patients [32-36]. Antibody production is characteristic of an activated adaptive immune system or that an individual has been exposed to a foreign antigen; elevations of autoantibodies (antibodies against self) are a hallmark of autoimmune disease.

Our data strongly suggest that POTS is an autoinflammatory condition, yet the current literature suggests it is an autoimmune disease. Pure autoinflammatory diseases are strongly associated with fever; POTS patients are known to have difficulty regulating body temperature. These conflicting hypotheses can be rationalized by considering that POTS has a "mixed" inflammatory signature. There are a number of recent reports in the literature providing evidence of mixed-pattern diseases [29,37-39]. We found that POTS patients had elevations of the proinflammatory cytokines IL-1 $\beta$, IL-6, IL-18, and INF $\gamma$, which have been reported in both autoinflammatory and autoimmune diseases and, potentially, are a result of abnormal NK cell function [40].

Other elevated proinflammatory biomarkers included IL-17 ( $p<0.0001)$, MCP-1 $(p<0.0002)$, and RANTES ( $p<0.0001$; an indicator of platelet activation), whereas the proinflammatory $\mathrm{TNF} \alpha$ was found to be at a similar concentration to that in non-POTS subjects. Interestingly, our pilot study found elevations of TNF $\alpha$ [11]. Tumor necrosis factor alpha is a cytokine of the innate immune system involved in acute phase reactions and produced primarily by activated macrophages and by T helper and NKT cells in response to IL-1 [41]. More recently, TNF $\alpha$ has been reported to induce the inflammasome-independent production of IL-1 $\beta$, causing autoimmunity [42]. CD30, which is part of the TNF family and regulates cell proliferation, was elevated in both our pilot study and this investigation.

CD30 is not expressed on resting or naive T and B cells but is a biomarker of both types of activated lymphocytes. It is elevated in both autoimmune and chronic inflammatory diseases [43]. It is released from the surfaces of activated T cells, B cells, and NK cells and has been used as a biomarker in a number of studies to predict renal allograft rejection [44]. CD30 is cleaved from the surfaces of these activated cells and circulates in the peripheral blood as soluble (s)CD30. Elevation of CD30, among other biomarkers, has been reported to be associated with an increased risk for the development of non-Hodgkin lymphoma, as well as resulting from viral infection such as EBV and HIV [45]. We have postulated that 
a viral infection may be the initiating stimulus for the development of autoantibodies in POTS; the results reported here are consistent with the premise but it requires additional research $[9,11]$.

Other regulatory cytokines found to be elevated in this study were IL-10 $(p<0.0001)$ and IL-21 ( $p<0.003)$; these biomarkers would be expected to be elevated as feedbacks to turn-off the innate immune system. One of the major functions of IL-10 is a suppressive effect on $\mathrm{T}$ cell subsets as an anti-inflammatory cytokine, principally secreted by Treg cells [41]. IL-21 is produced by CD4 + T cells, natural killer T cells (NKT), and follicular helper T cells and induces B cell proliferation and differentiation into plasma cells [41]. Of particular interest, elevation of IL-21 has been reported in autoimmune diseases including celiac disease (CD), rheumatoid arthritis (RA), and systemic lupus erythematous (SLE) [46-48].

Cytokines and chemokines that we found elevated in POTS patients, in contrast to our non-POTS group, and that have been related to autoimmune diseases, include not only IL-21, but also IL-1 $\beta$, INF $\gamma$, CD30, and IL-17 [49-51]. Although these biomarkers are elevated in autoimmunity, as stated previously, they also play significant roles in both innate and adaptive immune responses. Our data support a mixed-pattern inflammatory disease to best categorize POTS [29].

The second specific aim of our study was to validate previous results that POTS patients have significant elevations of innate immune system biochemicals that are related to the platelet as an immune cell. We have validated our previous results, but what about the platelet and its role in POTS? POTS patients were found to be platelet delta granule storage pool deficient ( $\delta$-SPD), with a mean of $2.65 \pm 0.22 \mathrm{DG} / \mathrm{PL}$, compared to our non-POTS group, which had normal numbers of DGs (4.95 $\pm 0.11 \mathrm{DG} / \mathrm{PL})$ $(p<0.0001$; normal $=4.64 \pm 0.11)$. As previously mentioned, $\delta$-SPD is usually considered an autosomal dominant inherited disorder but may also be recessive and/or acquired. Consequently, why do POTS patients have platelet $\delta$-SPD? If the subjects in our study had inherited $\delta$-SPD, it might be possible that $\delta$-SPD is a risk factor for susceptibility to POTS. However, it may be a biomarker of innate immune system activation. We have empirical data that suggest that platelet $\delta$-SPD may be acquired in viral infections (Epstein-Barr virus) and in cases of chronic inflammation. Platelet $\delta$-SPD has been previously described in autoimmune diseases including SLE, RA, and Sjögren's syndrome [52,53]. Since platelets contain cytokines and chemokines common in both innate and adaptive immunity, it is possible that the association we have found with platelet $\delta$-SPD is evidence that this comorbidity is an acquired disorder, suggesting that the platelet may drive the mixed inflammatory profile of POTS $[16,20,54,55]$. This is an unanswered question that needs to be addressed in future investigations, requiring assessments of POTS patients who have recovered from the disorder. Ideally, such an investigation would include platelet analysis at the time of POTS diagnosis, and reassessed subsequently, at a sufficient time interval after the disorder's resolution.

There are a number of limitations of our study. The study was initiated at the height of the COVID-19 pandemic, when all existing prospective investigations at our institution were put on hold and new prospective protocols were not considered by our IRB office. Thus, we were relegated to a retrospective study with all of the inherent problems related to such investigations. We lacked specific clinical histories for samples including Beighton scores used to assess hyperflexibility; some of the POTS patient group may have had hypermobility spectrum disorders (HSD) or hypermobile Ehlers-Danlos syndrome (h-EDS), which can be associated with easy bruising. The potential that $\delta$-SPD may be associated with HSD or EDS rather than POTS cannot be ruled out. We identified POTS samples based upon clinical test orders of one of our authors (BPG). Non-POTS samples were selected based upon identifying tests that had been ordered by a number of hematologists interested in the diagnosis of unexplained bleeding; the selected samples had normal test results. Our control group should not be considered "normal subjects" as samples in this group had been evaluated for platelet $\delta$-SPD in patients with unexplained bleeding 
symptoms. It is entirely possible that a few of the non-POTS samples might have had an under-lying autoimmune disease. Regardless, most of the $p$ values generated by the linear discriminant analysis utilized to analyze cytokine and chemokine concentration variances between groups were extremely significant, with $p$ values $<0.0001$. We have initiated a large prospective study to assess an expanded list of cytokines/chemokines and to ensure that our healthy control group does not include subjects with bleeding symptoms or other medical conditions. This study is utilizing questionnaires to objectively score bleeding history, hyperflexibility, and dysautonomia (COMPASS 31).

\section{Conclusions}

In conclusion, we have validated results described in a previous report that POTS patients have elevated biomarkers of an activated innate immune system [11]. Although we postulated that POTS is an autoimmune disease mediated by T cells, similar to RA, psoriasis, systemic sclerosis, multiple sclerosis, and type- 1 diabetes $[42,51,56,57]$, the data provided herein suggest that POTS is a mixed inflammatory pattern disease. The elevated IL-1 family cytokines IL-1 $\beta$ and IL-18 are significantly elevated in POTS, a characteristic of an autoinflammatory disease. However, we and others, using a variety of techniques, have reported a number of different autoantibodies in POTS patients that would be consistent with an autoimmune disorder. Type 1 interferons that are characteristic of autoimmune disease were not elevated in our POTS patients. We currently have a prospective study in progress to examine the hypothesis that POTS is a T-cell-mediated disorder similar to RA.

Author Contributions: Conceptualization, W.T.G.; Data curation, P.M.K., J.A.C., B.L.K. and B.P.G.; Formal analysis, W.T.G. and S.A.K.; Investigation, W.T.G., B.L.K. and B.P.G.; Methodology, P.M.K. and J.A.C.; Project administration, W.T.G.; Supervision, W.T.G.; Writing-original draft, W.T.G.; Writing-review and editing, W.T.G. and B.P.G. All authors have read and agreed to the published version of the manuscript.

Funding: This research received no external funding.

Institutional Review Board Statement: The study was conducted in accordance with the Declaration of Helsinki and approved by the Institutional Review Board of The University of Toledo (UT IRB\#300951, approved on 13 March 2021.

Informed Consent Statement: Patient consent was waived as samples utilized had been submitted for clinical evaluation of potential platelet dense granule storage pool deficiency and test results had been reported for inclusion in patients' medical records. All material utilized was residual from the diagnostic assay and had been stored frozen as standard operational procedure in our laboratory. All samples were de-identified.

Data Availability Statement: All data that were generated during this research project are included in the manuscript.

Conflicts of Interest: The authors declare no conflict of interest.

\section{References}

1. Vernino, S.; Bourne, K.M.; Stiles, L.E.; Grubb, B.P.; Fedorowski, A.; Stewart, J.M.; Arnold, A.C.; Pace, L.A.; Axelsson, J.; Boris, J.R.; et al. Postural orthostatic tachycardia syndrome (POTS): State of the science and clinical care from a 2019 National Institutes of Health Expert Consensus Meeting-Part 1. Auton. Neurosci. 2021, 235, 102828. [CrossRef]

2. Arnold, A.C.; Ng, J.; Raj, S.R. Postural tachycardia syndrome-Diagnosis, physiology, and prognosis. Auton. Neurosci. 2018, 215, 3-11. [CrossRef]

3. Shouman, K.; Vanichkachorn, G.; Cheshire, W.P.; Suarez, M.D.; Shelly, S.; Lamotte, G.J.; Sandroni, P.; Benarroch, E.E.; Berini, S.E.; Cutsforth-Gregory, J.K.; et al. Autonomic dysfunction following COVID-19 infection: An early experience. Clin. Auton. Res. 2021, 31, 385-394. [CrossRef]

4. Goldstein, D.S. The possible association between COVID-19 and postural tachycardia syndrome. Heart Rhythm 2021, 18, 508-509. [CrossRef]

5. Chilazi, M.; Duffy, E.Y.; Thakkar, A.; Michos, E.D. COVID and Cardiovascular Disease: What We Know in 2021. Curr. Atheroscler. Rep. 2021, 23, 37. [CrossRef] 
6. Blitshteyn, S.; Whitelaw, S. Postural orthostatic tachycardia syndrome (POTS) and other autonomic disorders after COVID-19 infection: A case series of 20 patients. Immunol. Res. 2021, 69, 205-211. [CrossRef]

7. Schondorf, R.; Low, P.A. Idiopathic postural orthostatic tachycardia syndrome: An attenuated form of acute pandysautonomia? Neurology 1993, 43, 132-137. [CrossRef]

8. Gunning, W.T., 3rd; Karabin, B.L.; Blomquist, T.M.; Grubb, B.P. Postural orthostatic tachycardia syndrome is associated with platelet storage pool deficiency. Medicine 2016, 95, e4849. [CrossRef]

9. Gunning, W.T., 3rd; Raghavan, M.; Calomeni, E.P.; Turner, J.N.; Roysam, B.; Roysam, S.; Smith, M.R.; Kouides, P.A.; Lachant, N.A. A Morphometric Analysis of Platelet Dense Granules of Patients with Unexplained Bleeding: A New Entity of DeltaMicrogranular Storage Pool Deficiency. J. Clin. Med. 2020, 9, 1734. [CrossRef]

10. Dupuis, A.; Bordet, J.C.; Eckly, A.; Gachet, C. Platelet delta-Storage Pool Disease: An Update. J. Clin. Med. 2020, 9, 2508. [CrossRef]

11. Gunning, W.T., 3rd; Stepkowski, S.M.; Kramer, P.M.; Karabin, B.L.; Grubb, B.P. Inflammatory Biomarkers in Postural Orthostatic Tachycardia Syndrome with Elevated G-Protein-Coupled Receptor Autoantibodies. J. Clin. Med. 2021, 10, 623. [CrossRef]

12. Antoniak, S.; Mackman, N. Platelets and viruses. Platelets 2021, 32, 325-330. [CrossRef]

13. Schrottmaier, W.C.; Salzmann, M.; Badrnya, S.; Mussbacher, M.; Kral-Pointner, J.B.; Morava, S.; Pirabe, A.; Brunnthaler, L.; Yaiw, K.C.; Heber, U.M.; et al. Platelets mediate serological memory to neutralize viruses in vitro and in vivo. Blood Adv. 2020, 4, 3971-3976. [CrossRef]

14. Maouia, A.; Rebetz, J.; Kapur, R.; Semple, J.W. The Immune Nature of Platelets Revisited. Transfus. Med. Rev. 2020, 34, 209-220. [CrossRef]

15. Ponomarev, E.D. Fresh Evidence for Platelets as Neuronal and Innate Immune Cells: Their Role in the Activation, Differentiation, and Deactivation of Th1, Th17, and Tregs during Tissue Inflammation. Front. Immunol. 2018, 9, 406. [CrossRef]

16. Lukasik, Z.M.; Makowski, M.; Makowska, J.S. From blood coagulation to innate and adaptive immunity: The role of platelets in the physiology and pathology of autoimmune disorders. Rheumatol. Int. 2018, 38, 959-974. [CrossRef]

17. Selle, F.; James, C.; Tuffigo, M.; Pillois, X.; Viallard, J.F.; Alessi, M.C.; Fiore, M. Clinical and Laboratory Findings in Patients with $\delta$-Storage Pool Disease: A Case Series. Semin. Thromb. Hemost. 2017, 43, 48-58. [CrossRef]

18. Yun, S.H.; Sim, E.H.; Goh, R.Y.; Park, J.I.; Han, J.Y. Platelet Activation: The Mechanisms and Potential Biomarkers. Biomed. Res. Int. 2016, 2016, 9060143. [CrossRef]

19. Patsouras, M.D.; Sikara, M.P.; Grika, E.P.; Moutsopoulos, H.M.; Tzioufas, A.G.; Vlachoyiannopoulos, P.G. Elevated expression of platelet-derived chemokines in patients with antiphospholipid syndrome. J. Autoimmun. 2015, 65, 30-37. [CrossRef]

20. Herter, J.M.; Rossaint, J.; Zarbock, A. Platelets in inflammation and immunity. J. Thromb. Haemost. 2014, 12, 1764-1775. [CrossRef]

21. Mai, D.B.; Smith, M.R.; Gunning, W.T., 3rd. Assessment of the Stability of von Willebrand Profile Clotting Factors and Platelet Dense Granule Testing Following Air Transport. Clin. Appl. Thromb./Hemost. 2018, 24, 1261-1266. [CrossRef]

22. Brunet, J.G.; Iyer, J.K.; Badin, M.S.; Graf, L.; Moffat, K.A.; Timleck, M.; Spitzer, E.; Hayward, C.P.M. Electron microscopy examination of platelet whole mount preparations to quantitate platelet dense granule numbers: Implications for diagnosing suspected platelet function disorders due to dense granule deficiency. Int. J. Lab. Hematol. 2018, 40, 400-407. [CrossRef]

23. Ribeiro, L.S.; Migliari Branco, L.; Franklin, B.S. Regulation of Innate Immune Responses by Platelets. Front. Immunol 2019, 10, 1320. [CrossRef]

24. Eisinger, F.; Langer, H.F. The Mutual Relation of Platelet Activation and Innate Immunity. Hamostaseologie 2018, 38, 186-202. [CrossRef]

25. Semple, J.W.; Italiano, J.E., Jr.; Freedman, J. Platelets and the immune continuum. Nat. Rev. Immunol. 2011, 11, 264-274. [CrossRef]

26. Rolfes, V.; Ribeiro, L.S.; Hawwari, I.; Böttcher, L.; Rosero, N.; Maasewerd, S.; Santos, M.L.S.; Próchnicki, T.; Silva, C.M.S.; Wanderley, C.W.S.; et al. Platelets Fuel the Inflammasome Activation of Innate Immune Cells. Cell Rep. 2020, $31,107615$. [CrossRef]

27. Stadhouders, R.; Lubberts, E.; Hendriks, R.W. A cellular and molecular view of $\mathrm{T}$ helper 17 cell plasticity in autoimmunity. J. Autoimmun. 2018, 87, 1-15. [CrossRef]

28. Shabgah, A.G.; Fattahi, E.; Shahneh, F.Z. Interleukin-17 in human inflammatory diseases. Postepy Dermatol. Alergol. 2014, 31, 256-261. [CrossRef]

29. Chetaille Nezondet, A.L.; Poubelle, P.E.; Pelletier, M. The evaluation of cytokines to help establish diagnosis and guide treatment of autoinflammatory and autoimmune diseases. J. Leukoc. Biol. 2020, 108, 647-657. [CrossRef]

30. van Kempen, T.S.; Wenink, M.H.; Leijten, E.F.; Radstake, T.R.; Boes, M. Perception of self: Distinguishing autoimmunity from autoinflammation. Nat. Rev. Rheumatol. 2015, 11, 483-492. [CrossRef]

31. Psarras, A.; Emery, P.; Vital, E.M. Type I interferon-mediated autoimmune diseases: Pathogenesis, diagnosis and targeted therapy Rheumatology (Oxford) 2017, 56, 1662-1675. [CrossRef] [PubMed]

32. Gunning, W.T., 3rd; Kvale, H.; Kramer, P.M.; Karabin, B.L.; Grubb, B.P. Postural Orthostatic Tachycardia Syndrome Is Associated With Elevated G-Protein Coupled Receptor Autoantibodies. J. Am. Heart Assoc. 2019, 8, e013602. [CrossRef] [PubMed]

33. Fedorowski, A. Postural orthostatic tachycardia syndrome: Clinical presentation, aetiology and management. J. Intern. Med. 2019, 285, 352-366. [CrossRef]

34. Badiudeen, T.; Forsythe, E.A.; Bennett, G.; Li, H.; Yu, X.; Beel, M.; Nuss, Z.; Blick, K.E.; Okamoto, L.E.; Arnold, A.C.; et al. A functional cell-based bioassay for assessing adrenergic autoantibody activity in postural tachycardia syndrome. J. Transl. Autoimmun. 2019, 2, 100006. [CrossRef] [PubMed] 
35. Watari, M.; Nakane, S.; Mukaino, A.; Nakajima, M.; Mori, Y.; Maeda, Y.; Masuda, T.; Takamatsu, K.; Kouzaki, Y.; Higuchi, O.; et al. Autoimmune postural orthostatic tachycardia syndrome. Ann. Clin. Transl. Neurol. 2018, 5, 486-492. [CrossRef]

36. Vernino, S.; Stiles, L.E. Autoimmunity in postural orthostatic tachycardia syndrome: Current understanding. Auton. Neurosci. 2018, 215, 78-82. [CrossRef]

37. El-Shebiny, E.M.; Zahran, E.S.; Shoeib, S.A.; Habib, E.S. Bridging autoinflammatory and autoimmune diseases. Egypt. J. Intern. Med. 2021, 33, 9. [CrossRef]

38. Peckham, D.; Scambler, T.; Savic, S.; McDermott, M.F. The burgeoning field of innate immune-mediated disease and autoinflammation. J. Pathol. 2017, 241, 123-139. [CrossRef]

39. Hedrich, C.M. Shaping the spectrum-From autoinflammation to autoimmunity. Clin. Immunol. 2016, 165, 21-28. [CrossRef]

40. Frizinsky, S.; Haj-Yahia, S.; Machnes Maayan, D.; Lifshitz, Y.; Maoz-Segal, R.; Offengenden, I.; Kidon, M.; Agmon-Levin, N. The innate immune perspective of autoimmune and autoinflammatory conditions. Rheumatology (Oxford) 2019, 58, vi1-vi8. [CrossRef]

41. Akdis, M.; Aab, A.; Altunbulakli, C.; Azkur, K.; Costa, R.A.; Crameri, R.; Duan, S.; Eiwegger, T.; Eljaszewicz, A.; Ferstl, R.; et al. Interleukins (from IL-1 to IL-38), interferons, transforming growth factor $\beta$, and TNF- $\alpha$ : Receptors, functions, and roles in diseases. J. Allergy Clin. Immunol. 2016, 138, 984-1010. [CrossRef] [PubMed]

42. Jain, A.; Irizarry-Caro, R.A.; McDaniel, M.M.; Chawla, A.S.; Carroll, K.R.; Overcast, G.R.; Philip, N.H.; Oberst, A.; Chervonsky, A.V.; Katz, J.D.; et al. T cells instruct myeloid cells to produce inflammasome-independent IL-1 $\beta$ and cause autoimmunity. Nat. Immunol. 2020, 21, 65-74. [CrossRef] [PubMed]

43. Barbieri, A.; Dolcino, M.; Tinazzi, E.; Rigo, A.; Argentino, G.; Patuzzo, G.; Ottria, A.; Beri, R.; Puccetti, A.; Lunardi, C. Characterization of CD30/CD30L(+) Cells in Peripheral Blood and Synovial Fluid of Patients with Rheumatoid Arthritis. J. Immunol. Res. 2015, 2015, 729654. [CrossRef] [PubMed]

44. Wieland, E.; Shipkova, M. Lymphocyte surface molecules as immune activation biomarkers. Clin. Biochem. 2016, 49, 347-354. [CrossRef] [PubMed]

45. Makgoeng, S.B.; Bolanos, R.S.; Jeon, C.Y.; Weiss, R.E.; Arah, O.A.; Breen, E.C.; Martinez-Maza, O.; Hussain, S.K. Markers of Immune Activation and Inflammation, and Non-Hodgkin Lymphoma: A Meta-Analysis of Prospective Studies. JNCI Cancer Spectr. 2018, 2, pky082. [CrossRef] [PubMed]

46. Niu, X.; He, D.; Zhang, X.; Yue, T.; Li, N.; Zhang, J.Z.; Dong, C.; Chen, G. IL-21 regulates Th17 cells in rheumatoid arthritis. Hum. Immunol. 2010, 71, 334-341. [CrossRef]

47. Gensous, N.; Schmitt, N.; Richez, C.; Ueno, H.; Blanco, P. T follicular helper cells, interleukin-21 and systemic lupus erythematosus. Rheumatology (Oxford) 2017, 56, 516-523. [CrossRef]

48. Iervasi, E.; Auricchio, R.; Strangio, A.; Greco, L.; Saverino, D. Serum IL-21 levels from celiac disease patients correlates with anti-tTG IgA autoantibodies and mucosal damage. Autoimmunity 2020, 53, 225-230. [CrossRef]

49. Guan, Q.; Gao, X.; Wang, J.; Sun, Y.; Shekhar, S. Cytokines in Autoimmune Disease. Mediat. Inflamm. 2017, $2017,5089815$. [CrossRef]

50. Moudgil, K.D.; Choubey, D. Cytokines in autoimmunity: Role in induction, regulation, and treatment. J. Interferon Cytokine Res. 2011, 31, 695-703. [CrossRef]

51. Kunz, M.; Ibrahim, S.M. Cytokines and cytokine profiles in human autoimmune diseases and animal models of autoimmunity. Mediat. Inflamm. 2009, 2009, 979258. [CrossRef] [PubMed]

52. Lewandowski, K.; Zozulinska, M.; Samborski, W.; Zawilska, K. Acquired platelet storage pool deficiency in rheumatoid arthritis. Pol. Arch. Med. Wewn 1991, 86, 46-52. [PubMed]

53. Bolton-Maggs, P.H.; Chalmers, E.A.; Collins, P.W.; Harrison, P.; Kitchen, S.; Liesner, R.J.; Minford, A.; Mumford, A.D.; Parapia, L.A.; Perry, D.J.; et al. A review of inherited platelet disorders with guidelines for their management on behalf of the UKHCDO. Br. J. Haematol. 2006, 135, 603-633. [CrossRef] [PubMed]

54. Tunjungputri, R.N.; Li, Y.; de Groot, P.G.; Dinarello, C.A.; Smeekens, S.P.; Jaeger, M.; Doppenberg-Oosting, M.; Cruijsen, M.; Lemmers, H.; Toenhake-Dijkstra, H.; et al. The Inter-Relationship of Platelets with Interleukin-1 $\beta$-Mediated Inflammation in Humans. Thromb. Haemost. 2018, 118, 2112-2125. [CrossRef]

55. Semple, J.W.; Freedman, J. Platelets and innate immunity. Cell Mol. Life Sci. 2010, 67, 499-511. [CrossRef]

56. Long, D.; Chen, Y.; Wu, H.; Zhao, M.; Lu, Q. Clinical significance and immunobiology of IL-21 in autoimmunity. J. Autoimmun. 2019, 99, 1-14. [CrossRef]

57. Meyer, O. Interferons and autoimmune disorders. Jt. Bone Spine 2009, 76, 464-473. [CrossRef] 